\title{
Getting Jacked and Burning Fat: Examining Doping and Gender Stereotypes in Canadian University Sport
}

\author{
Charlene Weaving \\ St. Francis Xavier University \\ Sarah Teetzel \\ University of Manitoba
}

\begin{abstract}
In this paper, the authors analyze the results of a three-year qualitative study examining Canadian female and male university student athletes' perceptions of gender and doping. Student athletes $(n=38)$ discussed their perceptions of doping, gender, and sport during in-depth, semistructured interviews. The results demonstrate the extent that student athletes continue to draw on gender stereotypes in assessing acceptable and unacceptable substance use in sport. Many of the student athletes interviewed acknowledged or applied extensive gender stereotyping in discussing their understanding of femininity and masculinity in sport. Women athletes, in particular, indicated they were hesitant to use both banned and permitted ergogenic supplements out of fear of becoming too muscular or masculine, while several male athletes expressed feeling pressure to appear muscular, especially if they wanted to be successful in traditionally male-dominated sports such as football. Applying previous theoretical work Lock by (2003) and Bartky (1990) to the themes resulting from the interviews, the authors argue that student athletes' attitudes toward doping remain engulfed in gender stereotypes. Because doping culture in the Canadian university system is entangled with gender stereotyping, doping education and prevention programs would benefit from taking these gender stereotypes into account, rather than pretending they do not exist.
\end{abstract}

Few qualitative studies examining doping culture in sport include analysis of the perspectives of athletes competing at the lower end of the high-performance spectrum; however, the majority of athletes training and participating in highperformance sport will not make it to the Olympic or professional level. Thousands of athletes competing at the university (varsity) level, arguably, have as much or

Weaving is with the Department of Human Kinetics, St. Francis Xavier University, Antigonish, Nova Scotia, Canada. Teetzel is with the Faculty of Kinesiology and Recreation Management, University of Manitoba, Winnipeg, Manitoba, Canada. Address author correspondence to Charlene Weaving at cweaving@stfx.ca. 
more to gain from using banned substances and methods as other subpopulations of athletes as they seek to gain entry into the elusive world of professional sport. University student athletes must adhere to the World Anti-Doping Code (2014) and avoid the use of all substances and methods listed on the World Anti-Doping Agency's prohibited list. Yet there has been a lack of attention given to the experiences of university student athletes, particularly female athletes, in the sport sociocultural literature. ${ }^{1}$ To help address this gap, we recruited 38 university student athletes from three Canadian universities to share their perceptions of the intersections of doping, gender, and sport. In analyzing the culture of Canadian university sport, we attempt to discern the role that gender stereotypes play in student athletes' understanding of doping and gender in sport.

Researchers have noted the complex relationship between doping and gender, as well as between the gender verification and drug testing processes (Sailors, Teetzel \& Weaving, 2012). Both tests, introduced in high-performance sport in the late 1960s, are intended to level the playing field, promote fairness, and reduce instances of cheating (Beamish \& Ritchie, 2005). The majority of research analyzing the intersection of gender and doping in sport remains focused on sex verification. For example, Davis and Edwards' (2014) examination of the International Association of Athletics Federations (IAAF) policy on hyperandrogenism and female eligibility in elite sport (IAAF, 2012), which the International Olympic Committee (IOC) endorsed before the 2012 London Olympic Games (IOC, 2012), demonstrates policies continue to "function as a way of determining who can compete as a woman in sporting competition and who cannot" (Davis \& Edwards, 2014, p. 46). These policies reinforce the oversimplified assumption that disparity in sport performance between men and women is the only reason for maintaining sex-segregated sport. In light of the IAAF's statement that women athletes with so-called 'disorders of sex development' "often displayed masculine traits and have an uncommon athletic capacity in relation to their female competitors" (Davis \& Edwards, 2014, p. 47) Davis and Edwards point out that the IAAF's position is unsupported by evidence and contains vague assumptions about masculinity and femininity in sport.

Some people and sports organizations can appear to be more concerned with female athletes failing to meet societal gender norms than cheating via doping. The American media's initial coverage of track and field athlete Marion Jones as a "queen" and "the world's fastest woman," while simultaneously presenting her then husband C.J. Hunter as "beastly" exemplifies this idea. By framing the Jones/ Hunter story as a fairytale for many years, highlighting "the imagery and dreams conveyed by her beauty and prowess" (Pfister \& Gems, 2013, p. 10), suspicions of performance-enhancing drug use by Jones were negated and trumped by her heterosexual appeal. As Rebecca Ann Lock (2003) argued, "the dislike of female dopers is similar to the dislikes of lesbians and women who are considered 'ugly', for such female athletes fail to meet the criteria of heterosexual femininity" (p. 397). Lock's (2003) theoretical perspective on gender and doping in sport remains particularly relevant today. For Lock, doping is closely mirrored with Butler's (1990) heterosexual matrix of sex, gender and sexuality, which "accounts for how we make assumptions of what we see based on normative frameworks in society" (Tredway, 2013, p. 164).

The extent to which university student athletes see and experience connections between doping and the heterosexual matrix of gender, sex, and sexuality warrants 
examination. In Canada, university athletes compete in the Canadian Interuniversity Sport (CIS) system, which is not immune to doping, yet very little scholarly analysis of doping in the CIS has been conducted. ${ }^{2}$ Historically, research on Canada's doping culture has focused solely on the elite Olympic level, for example, the infamous 1988 Ben Johnson steroid scandal, and the 1998 Ross Rebagliati snowboarding marijuana scandal (Kidd, 2013; Thorpe, 2012). The CIS is the equivalent governing body in Canada to the NCAA in the USA, but operates at a much smaller scale as approximately 11,000 student athletes participate in the CIS (versus 420, 000 in the NCAA) each year. To gain insight into the extent that doping culture in Canadian university sport is entangled with gender stereotyping, Lock's (2003) foundational theoretical work on gender, doping, and sport is combined with Bartky's (1990) framing of stereotyping as a form of psychological oppression that can threaten women's autonomy.

There is considerable evidence that persistent gender stereotypes can have detrimental effects on women and, in turn, women can begin to see themselves not as equals to men, but rather as inferior, and place too much emphasis on their bodily appearances (e.g., Calogero \& Jost, 2011; Heflict, Goldenberg, Cooper \& Puvia, 2011; Rudman \& Glick, 2001). Bartky (1990) stressed:

the 'intimations of inferiority' are clear: Not only must we continue to produce ourselves as beautiful bodies, but the bodies we have to work with are deficient to begin with. Even within an already inferiorized identity (i.e., the identity of one who is principally and most importantly a body), I turn out once more to be inferior, for the body I am to be, never sufficient unto itself, stands forever in need of plucking or painting, of slimming down or fattening up, of firming or flattening. (p. 29)

With this explanation, Bartky demonstrates why stereotyping is problematic and something about which we ought to be concerned. Highlighting the dangers of gender stereotypes, another influential feminist writer, Colette Dowling (2000) draws on empirical studies to demonstrate: "if you make a woman who's good at math more aware of being female, she'll do less well on math tests" (p. 53).

Canadian feminist scholars Hall (2002) and Lenskyj (2003) have led the way in addressing the impact and danger of gender stereotypes in sport, historically and in the present, including the potential for gender stereotypes to undermine performances. Common examples of gender stereotypes in sport include the labeling of some male athletes as "dumb jocks" and female athletes who play softball, soccer, ice hockey and rugby as "masculine" and "butch." According to Hall (2002):

So long as women participated in 'beauty producing' sports like figure skating, synchronized swimming, or gymnastics, and as long as they looked feminine on the tennis or badminton courts, golf courses and ski hills, they would not be criticized. But athletes sweating on the basketball courts, softball pitches, ice hockey rinks, and the cinder tracks were suspect, their femininity (although rarely their sexuality) continually questioned. (p. 109)

Similarly, Lenskyj (2003) argues that traditional stereotypical thinking links femininity among women and masculinity among men with norms of heterosexuality; on the other hand, women and men lacking these characteristics are presumed 
to be lesbian or gay. Consequently, sport continues to emphasize hegemonic and heterosexual masculinity, and if one doesn't fit the "mold," they may experience stereotyping.

The extent to which university-aged athletes are cognizant of and use gender stereotypes of this nature is unclear. In analyzing student athletes' responses to questions about their understanding of femininity and masculinity, gender and sex, and social constructions of gender, doping, and sport, this paper explores the extent that student athletes have internalized what might be considered outdated gender stereotypes involving gender and doping. We then demonstrate that antidoping education and prevention programs, aimed at educating student athletes of their responsibilities in ensuring they remain eligible to represent their universities in sport, need to take into account these gender stereotypes.

\section{Methods}

To gain insight into how university student athletes interpret and make sense of the connections between doping and gender, a thorough annotated bibliography addressing the key arguments found in the literature on doping and gender, published in scholarly sources from the late 1960 s to 2012, was created. The annotated bibliography was then used to construct an interview guide for addressing student athletes' perceptions of gender, doping and sport. Semistructured, open-ended interviews were conducted with a sample of 38 Canadian student athletes competing at three Canadian universities. This method was selected because it allows for "the emergence of important themes that may not emerge from a more structured format" (Graton \& Jones, 2010, p. 157) to "shed light on theoretical curiosities and problems" (Atkinson, 2007, p. 42).

After obtaining research ethics board approval from the universities involved, and then recruiting participants at team orientation sessions and through posters advertising the study, we scheduled interviews with student athletes who volunteered to participate. After signing an informed consent form, each participant took part in a one-on-one, face-to-face interview with one of the members of the research team. Snowballing occurred in recruitment, as some individuals who initially volunteered for the study encouraged their teammates to also participate. The sample consisted of 17 women and 21 men who were members of a CIS team in one of seven sports, including: rugby, football, ice hockey, soccer, basketball, volleyball, and athletics. The specific breakdown of participants is illustrated in Table 1.

Each interview lasted between 30 and 45 minutes and participants were encouraged to speak freely and openly about their experiences and perceptions. The goal was for the interview to adopt a conversational style rather than a question and answer period. The interview began with general background questions about their sporting experiences, and moved to a discussion about individual preparation and diet. Participants were next asked about their take on university culture and doping and what substances they thought university athletes used. Participants were also questioned about body image and ideal body sizes for certain sports, coping with injuries, and recreational drugs. See Appendix A for the complete interview guide. Overall, based on the amount of information shared, participants were quite keen to discuss doping and gender in sport. 


\section{Table 1 Participant Characteristics}

\begin{tabular}{lll}
\hline$\#$ of Participants & Identification & Sport \\
\hline 1 & Female & Rugby \\
5 & Male & Football \\
1 & Female & Ice hockey \\
9 & Male & Ice hockey \\
1 & Female & Soccer \\
7 & Female & Basketball \\
2 & Male & Basketball \\
5 & Female & Volleyball \\
3 & Male & Volleyball \\
2 & Female & Cross country \& track \\
2 & Male & Cross country \& track \\
\hline
\end{tabular}

All interviews were recorded and checked against the audio recordings after transcription to ensure precision and accuracy. After the interviews were transcribed, student athletes were invited to review and alter their transcripts if they wished as a form of member checking (Creswell, 2007). We coded the reviewed and approved transcripts using both priori and emergent coding techniques (Tesch, 1990). Despite each participant having an individual sport experience, the coding process elicited several themes, which are discussed in the next section. Throughout the data collection process, we took notes and attempted to reflect on both our role and the emerging themes. Through this reflexive process, we attempted to identify our own personal biases and temper some of the known methodological concerns that plague researchers attempting to study athletes' doping behaviors.

The methodological issues and constraints associated with obtaining accurate information about socially stigmatized behaviors, such as doping, have been known for many decades. Hyman's (1944) study of whether people cashing in war bonds would admit to doing so demonstrated that people implicated in socially unacceptable behaviors are unlikely to disclose their involvement if they fear negative repercussions will occur (Yesalis, Bahrke, Kopstein \& Baruskiewicz, 2000). In doping research, it is difficult to use self-reported data to obtain accurate information because participants may be unwilling to disclose their knowledge or beliefs. As many researchers since Hyman have shown, participants engaging in undesirable behaviors have a tendency to provide what they think are socially-desirable responses to researchers (Petróczi \& Nepusz, 2011). By speaking with the student athlete participants after their seasons and academic years were completed, and by asking about their overall perceptions of substance use in the CIS, rather than their own experiences or involvement with banned performance-enhancing drugs and methods, we tried to minimize some of these methodological constraints, improve trustworthiness, and obtain as rich and accurate responses as possible. 


\section{Findings}

Perspectives shared by CIS student athletes suggest that extensive gender stereotyping is present in their understanding of femininity and masculinity in sport, and that student athletes' attitudes toward doping remain engulfed in gender stereotypes. Results from the interviews indicate that many of the student athletes participating in the study view doping in sport through a gendered lens. Five themes emerged from the coding process, which together shed light on the prevailing gender stereotypes Canadian university athletes hold regarding gender and doping: (a) femininity means feminism; (b) drugs are masculine, feminine or gender neutral; (c) muscles are masculine; (d) women athletes need skill, not strength; and (e) weight loss supplements are for women. These five themes demonstrate that student athletes rely on stereotypes when discussing gender, doping, and sport.

\section{Femininity Means Feminism}

To gain an understanding of the culture of doping at the university level, we began each interview by asking the participant what the terms "femininity" and "masculinity" imply to them within the context of sport. Specifically, we asked, "how would you describe femininity/masculinity" and "what do you think femininity is/involves?" Answers varied extensively, but many participants linked femininity with feminism in their responses, despite none of the interview questions addressing feminism. Associating femininity with feminism demonstrates a shift in the meaning of the word feminism. ${ }^{3}$ A clear lack of understanding of the terms femininity and masculinity was evident among many of the student athletes. For example, one participant responded, "feminine is not burping while wearing a dress." This comment emphasizes traditional views of femininity where the student athlete associates femininity with certain types of dress, namely wearing a dress. For this participant, the action of burping while wearing a dress is not considered feminine, and femininity implies women behaving and looking a certain way. In the same vein, a female hockey player described masculinity as the expectation, "Men don't cry...so if you're masculine no crying. They work out a lot. Basically I think that masculinity is rough." Moreover, a male football player's description of femininity and masculinity also reinforced gender stereotypes:

Femininity is girly girls with the high voice, ditzy, and likes pop culture. Masculinity, the image that comes to my mind is the perfect male with chiseled abs and bronze skin and can do anything athletically. He is very talented and a typical male ego of being head honcho.

These examples indicate a general lack of understanding of the terms femininity and masculinity.

Many participants acknowledged their answers were based on gender stereotypes they were uncomfortable holding. Specifically, several participants explained that while they may not agree with the extent of stereotyping surrounding university sport culture, they recognize that it exists.

Bartky (1990) argues that stereotyping can threaten the development of autonomy and moral agency. Women become conditioned not to adopt the same kind 
of autonomous development that males do. Several participants were aware that their responses about masculinity and femininity in sport were steeped in gender stereotypes, including one female basketball player in explaining her conception of masculinity: "Stereotypically, strong... when I think of males they take care of people and that type of thing. Aggressive too a little bit I would say, but then not really, I'm just thinking stereotypically because I don't really know." After reflecting on their conceptions of femininity and masculinity, the student athletes in the study were asked to identify performance-enhancing drugs, substances, methods and supplements they considered to be masculine, feminine and gender neutral.

\section{Drugs Are Masculine, Feminine, or Gender Neutral}

All participants were asked to provide specific examples of substances, both banned and permitted in sport, that they considered "masculine" or "feminine" or "gender neutral." The first list includes substances the 38 participants identified (in alphabetical order) that they are aware some male university athletes, specifically, use to enhance athletic performance and consequently they considered masculine substances: creatine, clenbuterol, energy supplements, NO explode, glycogen booster, human growth hormone, size-on supplement, anabolic steroids (injectable, Winstrol, Dianabol), super pump supplement, whey protein, and a variety of other protein powders. Participants considered the above substances to be masculine in nature, simply because male athletes in the CIS were thought to use them. Moreover, many of the substances identified above fit into the categories of protein supplements and anabolic steroids, both of which promote muscular growth and development, traits that are associated generally more with males and masculinity than females and femininity.

In contrast, participants indicated that the following substances are used by female university athletes and are considered to be feminine, specifically: energy supplements, ephedrine, iron supplements, MPower, pain killers, protein powders, and weight loss supplements (e.g., Hydroxy-Cut). As will be discussed in more detail in the following space, both male and female participants believe many female student athletes use weight loss supplements, as well as energy products and pain killers, for performance-enhancing purposes. While some weight loss supplements contain ephedrine, pseudoephedrine, and/or diuretics that WADA bans from use in sport, none of the participants listed traditional banned performance-enhancing drugs, such as steroids, human growth hormones, or blood boosters, as substances female student athletes were likely to take.

There is evidence of gender differences in doping behaviors. For example, Peters et al. (2005) found that male athletes reported that they used the drug Ephedra to enhance athletic performance while female athletes stated they used the drug primarily for weight loss purposes rather than to enhance performance directly. In addition, Mueller et al.'s (2009) survey of 241 female and male collegiate athletes' use of appearance and sport enhancers concluded that female athletes were more likely to consume dietary substances to decrease body fat whereas male athletes were more likely to use steroid-based substances to increase body size. Canadian university student athletes echoed these findings.

Participants considered protein powder supplements, caffeine and energy drinks to be gender neutral ergogenic substances, meaning that both men and women 
reported student athletes in Canada consume these products. Specifically, protein supplements were considered equally acceptable for both female and male student athletes to consume as well as the most popular supplement used by university athletes. One male football player describes the importance of protein powder to athletes noting, "Protein powder is like water to an athlete." Similar findings are outlined in Mueller et al.'s (2009) study: both male and female collegiate athletes reported that consuming protein shakes was a normal behavior for male and female athletes.

Canadian student athletes who suggested protein powder is now used equally by male and female athletes added that it is easily accessible and marketed as a necessary, healthy supplement to healthy eating, which can help athletes recover quickly. The recovery aspect of protein powders means student athletes associate it with multiple purposes, not just muscle building, which could explain why participants considered it specific to neither sex exclusively. One male volleyball player explained that a shift in viewing protein as a muscle-building supplement only for male strength athletes to become a common, gender neutral substance had occurred: "I think protein powders used to be more male, but with all these new studies it has been proven to be beneficial. I think it's more balanced just as many girls take protein powder." However, his teammate, also a male volleyball player, noted he thought male athletes use protein powders to improve their physical appearance (i.e., obtain shapely and large muscles and sculpted abdominals) more than female athletes do, explaining: "Guys take protein powders because they want that beach body perception. I think it's the reason those guys are taking it to be honest."

Comments associating protein powders with muscular physiques were common. For example, a female basketball player discussed how she was in the process of deciding whether she should incorporate protein powders into her diet, but worried about gaining muscle mass: "I started a pretty crazy training schedule, I work out every day, and I've been told to look into protein powders and stuff just because of the amount I've worked out. So it'll bulk me up way faster, but I'm not sure if I want to be really ripped type of thing. I'm thinking and mulling it over." Despite noting the social acceptability of female athletes consuming protein supplements, many women still noted their fears of becoming what they considered excessively muscular, a trait strongly associated with male student athletes. This idea is analyzed further below.

\section{Muscles Are Masculine}

It was clear that many female student athletes remain hesitant to use muscle building supplements, or to "bulk up," because many associate a muscular body with masculinity and male athletes. For example, a female volleyball player noted, "Girls aren't supposed to be jacked, per say, that's not the view of society." Espousing the idea that developed musculature is normal for men but abnormal for women, a male hockey player added: "You would be able to tell if the woman was on steroids pretty easily but whereas guys, if you're not an idiot about it you don't have to look like you're on steroids." These representative statements all connect the idea that large muscles are associated with an acceptable male physique and an unacceptable female physique. These student athlete perspectives reinforce research suggesting that because sport remains one of the lasting domains for maintaining traditional 
patterns of male dominance and female subordination, women who take steroids are critiqued not for risking their health but for confusing gender ideals in becoming so muscular (Burke, 2004).

Some student athletes noted women may worry their trapezius ("traps") muscles will become visible if they get too strong. A male football player discussing women and muscular development noted, "I don't think that girls want to get jacked. They want to look good in a bikini and a tight dress. They don't want to have biceps bulging out or traps. I hear from girls that have traps and they try to get rid of them." Several women in the study echoed sentiments of this nature. For example, a female cross country athlete explained, "girls aren't really into supplements as much as guys because they don't want to bulk up, and usually when you hear about supplements it's to bulk up." A female hockey player echoed similar ideas in describing how some of her teammates requested their training involve less strength work: "Some of the females last year in our training program emailed the coach and said they were putting on bulk and that's not what they want, so he had to modify it." Comments of this nature were appearance-driven and did not include reflection on whether "losing" strength and size would decrease their athletic performance.

The fear of increased musculature expressed by the participants relates to gender stereotypes of femininity and masculinity idealized norms. Specifically, many women student athletes in Canada remain hesitant to develop an overly muscular body in fear that they will no longer be considered appropriately feminine or "womanly" outside of the sport context. A female hockey player outlined her concern about gaining muscle as a woman playing a traditionally male-dominated sport, noting: "I guess the only sports that would really need a lot of bulking up would be the contact sports, and I think there is so much already, like stereotyping going on. They might not want to do it just because like, they may think, I'm already playing a masculine sport, and if I take supplements, it may lead people to think differently about me." In similar statements, several student athletes demonstrate the prominence of gender dichotomization in doping and sport discussions. Many participants described how female student athletes were hesitant to be become too muscular because of fear of being labeled masculine or lesbian.

Like Lock's (2003) analysis of the parallels between female dopers, unattractive women, and lesbians that posits all contravene the expectations of heterosexual femininity, participants' reinforced the idea that people make assumptions about muscular women's sexual orientation. Lock (2003) suggests excess muscularity for women implies the woman is "butch" or homosexual, and "people are disgusted by the idea of women dopers, because doping is typically equated with the effects of "masculinization"' (p. 398). Associating femininity with heterosexual attractiveness and labeling athletes as "ugly" if they have a muscular build similar to men leads to the dangerous belief that considers lesbianism "as an aesthetic that matches the offensive aesthetic of masculinized female dopers" (Lock, 2003, p. 408). Similarly, Cahn (2010) argues that the lesbian stereotype in sport has traditionally functioned to pressure female athletes to display visible markers of femininity and heterosexuality, an action sociologists refer to as the female apologetic in sport. Comparable claims were made by some of the participants (both male and female athletes) regarding homosexual stereotyping and doping.

Most notable, a female hockey player bluntly explained, "They [female athletes] don't want to get bulky and look gay." A male volleyball player's assessment 
captures Lock and Cahn's observations as well: "They [female athletes] are either feminine or butch." Many participants echoed outdated stereotypes about appropriately feminine-looking body types and physiques. However, there was awareness by the participants making these statements that they are based on stereotypes, and many participants were cognizant of the tensions they felt in using stereotypes of this nature to inform their answers, as they were when describing their interpretations of masculinity and femininity. For example, according to a female rugby player, "I think there is a lot of female athletes in masculine sports, who like kind of feel they need to prove themselves, not so much in rugby, but outside of rugby. A lot of players get dolled up and everyone is like, 'whoa you guys clean up really well', and it's like, 'well we're still women, we can dress in dresses and stuff." 'In other words, the participants understood that claiming muscularity to be masculine and associating lesbianism with musculature was inaccurate and even homophobic, yet emphasized that this was an accurate description of the current culture in university sport.

Beyond fears of bulking up, several of the student athletes participating in this study noted only male athletes require large muscle for success. As a male hockey player explained, "obviously for women if you're going to be taking steroids and can bench press 400 pounds, it's not going to do much, but if you're a guy and you can bench press 400 pounds, you can play in the NFL." Two male football players offered additional insight into their beliefs that steroid use is only beneficial for male athletes, with one noting, "I would be way more surprised to hear if girls took steroids and the next question would be what is she doing it for, is she a butch bodybuilder?" and the other explaining, "Any time I think of steroids the first picture I think in my head is some big juice monkey looking guy and I never picture a girl, it's always a big guy." Connected with the stereotype that only male strength athletes and butch lesbian women would want bigger muscles is the belief that women's sport does not require muscularity and strength like men's sport does for success. The underlying perception associated with these sentiments is that female athletes should not be or do not need to be as strong (or as muscularly defined) as male athletes. As Lock (2003) points out, "Being accused of looking like a man is said as if it is the gravest insult there is for a woman" (p. 405).

\section{Women Athletes Need Skill, Not Strength}

Several participants expressed strong views that success in women's university sport requires more emphasis on skill than on great strength. One can interpret this idea as a negative view of women's sport, because the underlying assumption is that weaker athletes can achieve success in women's events, but would be less successful competing against men. Participants also expressed the idea that there is much more pressure and necessity for males to be "big" to be successful in their sports, hence male athletes would be more inclined to use substances that increase strength. A male basketball player explains this perceived difference: "Women's sport is more skill based rather than athleticism type of thing. And females can be very small and skilled and still make it. But if a male is really small but really skilled his chances of making it are really tough compared to someone who is already a big size." Athletes expressing these sentiments failed to realize the range of advantages associated with skill and strength in both men's and women's sports, 
and instead relied on outdated stereotyping and classification. For instance, there was no mention that women rugby players (a contact sport involving tackling) would require strength to be successful, or that in other sports, such as volleyball and soccer, strength is needed to spike a volleyball or kick a goal. While the sample of participants involved both male and female ice hockey players, female and male basketball players and a female rugby player-sports which emphasize both strength and skill - participants associated strength only with male athletes. This tendency matches Warner and Dixon's (2013) findings that women are often considered unsuited for sport due to being less aggressive and competitive than men.

Fueling these perceptions is the fact that in Canada semiprofessional and professional leagues are only available for male athletes (and a few exceptionally talented female athletes who qualify to compete in men's leagues) after they graduate or run out of eligibility to participate in the CIS. As several participants explained, university sport for men (especially those in football and hockey) can be a stepping stone to professional sport, whether it involves the Canadian Football League (CFL) or various hockey leagues around the world such as the American Hockey League (AHL). One male hockey player clarified, "So the guys are looking for a pro career, they're spending more time on the game, out on the ice more and in the gym trying to get that advantage, and with that... more use drugs and the need to get the edge on the next guy." However, comparable opportunities for women student athletes do not exist and, as a result, "I could see that men would be more prone to taking it to have that chance of an extra couple million dollars where in the WNBA there isn't that money" a male football player contextualizes.

University-level sports mark the top level of high-performances competition for women athletes in Canada unless they are selected as members of a national team. ${ }^{4}$ Correspondingly, participants believed women student athletes do not participate in their varsity sports the same ways as male student athletes attempting to attract the attention of professional scouts do, as women do not have as much to gain or as much pressure to consistently perform well. Because of the lack of professional opportunities for women athletes after the CIS, women's sports in the CIS are stereotyped as not being as important as men's programs, which could contribute to the ideas expressed above that women's sports require less strength for success. The rationale that women's sport does not require strength, and thus doping, because comparable professional opportunities are not available, can be interpreted as a backhanded compliment to the female athletes. Young (2005) argues that women's physical movements are stereotyped and characterized to be feminine and not as skilled as male athletic performances, explaining:

The relatively untrained man nevertheless engages in sport generally with more free motion and open reach than does his female counterpart. Not only is there a typical style of throwing like a girl, but there is a more or less typical style of running like a girl, climbing like a girl, swinging like a girl, hitting like a girl. (p. 33)

Young claims that women tend to underestimate their bodily capacities. Yet, regardless of whether there are professional opportunities, dichotomizing women's sports to mainly involve skill and men's sports to emphasize strength rests in gender stereotypes, which reinforce the outdated belief that men's sport is more important and of higher value. 


\section{Weight Loss Supplements Are for Women}

All participants interviewed considered weight loss supplements to be "feminine" drugs and the most prominent ergogenic substance used by women university student athletes. An example of the view that weight loss supplements are more acceptable for female athletes to take than male athletes is expressed in the following statement by a male hockey player: "if you're taking a weight-loss pill you would think that ooooh that's for females, you're taking a female pill." More diplomatically, a male football player observed, "I do think that girls who want to lose weight might turn to supplements that may help them lose weight more so than a guy."

Participants reported that women use weight-loss products in many cases to lose weight, while men were perceived to be more concerned with putting weight on to bulk up rather than lose weight. Athletes who participate in sports that require, or are believed to benefit from, a lean frame (such as volleyball, cross country running and track) were more concerned about weight compared with student athletes who participated in contact sports (such as rugby and ice hockey) that require more strength and mass. Participants suggested that societal pressures for women athletes to fit the ideal female body image could motivate athletes to use weight loss supplements as a way to achieve a certain body shape and size. Pressure from some coaches to maintain a low body fat percentage was noted by a female volleyball player who reported, "other countries like Brazil had a 15-18\% body fat limit and the coach here was trying to get us down to around 20." The rationale for using weight-loss pills like Hydroxy-Cut is to lose weight without feeling hungry, simply "take this pill and you don't have to eat," a female rugby player explains.

Body image issues are at play when athletes intentionally restrict their caloric intake to a point that can diminish not only their performance, but their health. Student athletes expressed concern that female teammates were jeopardizing their health to attain a desirable appearance. One female rugby player explained, "I know for a lot of people appearances are more important than health, but it's, like you're not eating and you're taking these energy sticks." The latter part of her comment highlights her skepticism and disapproval of these practices engaged in by some of her teammates. Student athletes participating in this study repeated the old assumption that women use substances to lose weight/mass while males use substances to gain weight/mass.

The sample of student athletes participating in interviews did not include male athletes from sports that require low body weight or involve weight cutting practices to make weight used by some rowers and wrestlers. It is possible that if athletes from these sports were included in this study, the use of weight loss supplements might not have been considered a women-only practice in sport. However, the sample did include two male runners who competed in both cross country and track-sports that require a smaller frame than football, for example. When asked if weight was important to their sport, neither male runner emphasized the need to lose or cut weight; instead they discussed the importance of maintaining a lean-frame, suggesting that ideal body weight levels vary depending on the event in which the athlete specializes. Consequently, not all track and field athletes need to maintain a low body weight:

With track you don't want to be too heavy, if you're a sprinter. If you're a long-distance runner you need to be a lot lighter because you don't even 
want to have a lot of muscle mass because it's heavier; and you don't want to carry that along. But if you're a sprinter, you want to be more hefty, but not too heavy. If you're a thrower you want to be bigger so you can control your center of gravity.

The same rationale applies to many other sports where athletes have specific roles. Several male student athletes discussed the need to maintain a healthy body, which they described as a "lean" body combining muscles mass and fitness. One male runner explained he believes other male runners desired to be "Pretty much be as light as possible, but there are some exceptions to that. I mean you can be surprised sometimes because larger people are better than small. So for the most part it's about staying relatively thin and muscular at the same time." In contrast, several female student athletes viewed weight loss supplements as a tool needed to aid weight loss without bulking up. As a female soccer player stated, "So females will use Hydroxy-Cut because it's aimed toward more weight loss as opposed to building muscle." Both male and female student athletes in this study highlighted the pressures women athletes feel to be a certain weight regardless of their sports. Even though athletes are expected to be strong and powerful, the North American ideals for women's bodies emphasize a Barbie doll figure (tall, long legs, very thin, and toned but not too muscular) and does not celebrate a typical athletic build (Schneider, 2000). University female athletes are sensitive of this ideal, and many continue to invoke images of this alleged ideal in their descriptions of feminineappropriate body practices in sport.

Historically female athletes have felt pressure to achieve a specific body weight to feel more comfortable in their uniforms. According to Davis and Delano (1992) female athletes sometimes "feminize" themselves when they avoid heavy weightlifting, wear styles of uniforms that connote sexuality, or "avoid body movements that connote strength, violence, or much aggression" (p. 14). For example, in CIS women's volleyball, the uniforms involve very short spandex shorts, commonly referred to as "booty-shorts," because they barely cover the athlete's buttocks. Brooks (2001) argues that volleyball uniforms (specifically the small bottoms) have resulted in women athletes dieting and overtraining to ensure that they look "sexy" in their uniforms. These sentiments supported the findings of Burke (2004), Davis and Delano (1992), and Lock (2003) who have specifically addressed gender constructions and doping in women's sport.

The term cosmetic doping, also known as vanity doping, refers to the use of drugs and supplements to enhance appearance, rather than to enhance athletic performance. While the substances vanity dopers ingest might be the same or similar to the ones standard dopers seeking competitive advantages in sport consume, the motivations of the users differ substantially. Thualagant's (2012) conclusion that "illegal substances and methods used in a fitness context are often for the enhancement of the individual's bodily appearance" (p. 409) is applicable here. Thualagant argues that individuals practice various doping techniques to alter their appearance to be more in line with societal ideals and norms regarding masculinity and femininity. Responses provided by many student athletes in this study suggest that they perceive weight loss substances help achieve a certain body ideal, which does not seem rooted in performance enhancement, but rather in appearance enhancement. The idea that weight-loss supplements can be dangerous, and can lead to unintentional doping violations, was not mentioned by participants in this study. 


\section{Implications}

Bastow (1992) asks us to consider the following statement: "Men should be strong, rationale, aggressive; women should be weak, emotional, submissive," and then reflect "to what extent do these images fit the majority of real people? That is, do men and women really conform to these images, or are these images stereotypes?" (p. 1). Similar questions can be posed in response to the student athletes' responses gathered through the interview protocol described above. Are images of the strong, muscular male athlete and the slim beautiful female athlete accurate? Clearly they are not the only options. The CIS features student athletes with a wide variety of body types and shapes.

Yet, many of the student athletes interviewed acknowledged or applied extensive gender stereotyping in discussing their understanding of femininity and masculinity in sport. Women athletes, in particular, indicated they were hesitant to use both banned and permitted ergogenic supplements out of fear of becoming too muscular or masculine, while several male athletes expressed feeling pressure to appear muscular, especially if they wanted to be successful in traditionally male-dominated sports, such as football. For these reasons, we argue that student athletes' attitudes toward doping remain engulfed in gender stereotypes, which fail to recognize the variety of body types present in sport. Moreover, from stories told during the interviews, many student athletes, who compete at one of the highest levels of sport in Canada, engage in practices that could hinder their athletic success to attain a body image in line with traditional ideals. This is not to say that all student athletes engage in these strategies and practices. Many athletes put performance first; yet a common theme in the interviews was that student athletes perceived other athletes continue to buy into the idea that male athletes should strive to get bigger and female athletes should strive to get leaner without getting bulkier.

Doping and supplement culture in the Canadian university sport system is entangled with gender stereotyping. As a result, we argue, doping education and prevention programs would benefit from taking these gender stereotypes into account, rather than pretending they do not exist. The student athletes' views expressed in the interviews are reminiscent of what Davis and Delano (1992) noted in their critique of gendered messaging in antidrug campaigns:

the anti-drug campaigns, by assuming, reinforcing, and helping to naturalize the notion of physical gender dichotomization, conceal the physical realities of many people, such as women with hairy faces and small breasts and men with protruding breasts and little body hair. The campaigns not only render the many whose physical selves do not fit dichotomous gender categories as invisible but also label such people as ugly, freakish, and disgusting. (p. 11)

For the student athlete population in Canada, the dichotomization highlighted by Davis and Delano remains an issue. As doping education seminars are mandatory for student athletes before they start each season, these forums seem like a potentially effective place to address stereotypes and myths about supplement and drug use in sport.

The gender stereotypes described above are not only outdated, inaccurate, and based on traditional patriarchal norms, but can be dangerous. As a result of continuing to buy into these stereotypes, student athletes might be prone to engage in disordered eating practices or commit accidental doping violations using either 
weight-loss products containing banned substances, such as ephedrine or diuretics, or muscle building supplements that contain banned substances not listed on the labels. From an economic perspective, it is also possible that student athletes are consuming more protein through supplements than their bodies can use and are consequently wasting their money. To enhance the current doping education seminars for university athletes, organizers need to be aware of the prevailing gender stereotypes that surround university doping culture. We suggest organizers implement a holistic approach in the delivery of these programs. They should be aware of psychological, ethical and social implications of doping when outlining the program to begin to debunk the outdated stereotypes. Moreover, it is time to acknowledge and stop ignoring the reality that women athletes are participating in various doping practices at the university level.

\section{Conclusion}

In this paper, we shed light on the culture of university sport and emphasize the extent of stereotyping surrounding doping in sport for females and males. Grounded in Bartky's (1990) work on stereotyping, which posits stereotyping is something we ought to be concerned about because it can threaten one's self-determination, this paper highlights that the gender stereotypes espoused by university student athletes in Canada are problematic. Allowing distorted views of doping practices to continue can dangerous if doing so promotes health problems such as disordered eating or the disvaluing of women's sport

Based on five gender and doping stereotypes that emerged as themes in a study of 38 Canadian student athletes perspective on gender, doping, and sport, we argue that doping education and prevention programs need to not only account for gender stereotypes but work to debunk outdated and potentially dangerous views. Specifically, university programs need to acknowledge the pressures male and female athletes face regarding body ideals, and the extent of homophobia surrounding female athletes and muscle development, when imparting doping and supplement information to student athletes.

\section{Notes}

1. For examples of the limited research examining doping and gender see Weaving \& Teetzel, 2012.

2. In March 2010 a doping scandal was uncovered at the University of Waterloo in Canada involving the trafficking of steroids and human growth hormone by a former university male football player. This scandal sparked an investigation into doping at the university level by a Task Force appointed by the Canadian Centre for Ethics in Sport. See Teetzel \& Weaving, 2014. See also CCES, 2010.

3. We did not ask participants to identify their area of study at university. Students in a liberal arts degree likely would have taken at least one university class where feminist theories are outlined. However, students pursuing science degrees may not have had any exposure to courses addressing feminism or feminist issues. Overall, the association of femininity with feminism is something that requires further study to see if other cohorts of participants espouse a similar misunderstanding of the term. Researchers have previously noted the lack of understanding of 
the term feminism among younger generations, particularly in young women and young men who have come to fear referring to themselves as 'feminists' (Baumgarder \& Richards, 2000).

4. Many Canadian women's national hockey players (including Canadian national team member Hayley Wickenheiser) participate on CIS hockey teams. In addition, the CIS women's rugby programs have become a feeder system to the National 7's and 15's rugby teams.

\section{Acknowledgements}

This project was funded by a World Anti-Doping Agency Social Science Research Grant.

\section{References}

Atkinson, M. (2007). Sport, gender and research method. In K. Young \& P. White (Eds.), Sport and gender in Canada (pp. 32-55). Don Mills, ON: Oxford University Press.

Bartky, S.L. (1990). Femininity and domination: Studies in the phenomenology of oppression. New York: Routledge.

Bastow, S.A. (1992). Gender stereotypes and roles (3rd ed.). Pacific Grove, CA: Brooks/ Cole Publishing.

Baumgardner, J., \& Richards, A. (2000). Manifesta: Young women, feminism, and the future. New York: Farrar, Straus and Giroux.

Beamish, R., \& Ritchie, I. (2005). The spectre of steroids: Nazi propaganda, Cold War anxiety, and patriarchal paternalism. The International Journal of the History of Sport, 22(5), 777-795. doi:10.1080/09523360500143406

Brooks, C.M. (2001). Using sex appeal as a sport promotion strategy. Women in Sport and Physical Activity Journal, 10(1), 1-16.

Burke, M. (2004). What would happen if a 'woman' outpaced the winner of the gold medal in the men's 100m? Female sport, drugs and the transgressive cyborg body. Philosophy in the Contemporary World, 11(1), 35-43. doi:10.5840/pcw20041115

Butler, J. (1990). Gender trouble: Feminism and the subversion of identity. New York: Routledge.

Cahn, S. K. (2010). From the 'muscle moll' to the 'butch' ball player: Mannishness, lesbianism, and homophobia in U.S. women's sports. In P. Davis \& C. Weaving (Eds.), Philosophical perspectives on gender in sport and physical activity (pp. 145-159). London: Routledge.

Calogero, R., \& Jost, J.T. (2011). Self-subjugation among women: Exposure to sexist ideology, self-objectification, and the protective function of the need to avoid closure. Journal of Personality and Social Psychology, 100(2), 211-228. PubMed doi:10.1037/a0021864

CCES. (2010). CCES announces four anti-doping rule violations from University of Waterloo football team testing including the first for an adverse analytical finding of human growth hormone in North America. CCES News Release. Retrieved from http://www. cces.ca/en/news-137-cces-announces-four-anti-doping-rule-violations

Creswell, J.W. (2007). Qualitative inquiry and research design: Choosing among five approaches. Thousand Oaks, CA: Sage.

Davis, L., \& Delano, L. (1992). Fixing the boundaries of physical gender: Side effects of anti-drug campaigns in athletics. Sociology of Sport Journal, 9(1), 1-19.

Davis, P., \& Edwards, L. (2014). The new IOC and IAAF policies on female eligibility: Old Emperor, new clothes? Sport. Ethics and Philosophy, 8(1), 44-56. doi:10.1080/1 7511321.2014 .899613

Dowling, C. (2000). The frailty myth: Redefining the physical potential of women and girls. New York: Random House.

Graton, C., \& Jones, C. (2010). Research methodologies for sport studies (2nd ed.). Oxon: Routledge. 
Hall, M.A. (2002). The girl and the game: A history of women's sport in Canada. Peterborough, ON: Broadview Press.

Heflict, N.A., Goldenberg, J.L., Cooper, D.P., \& Puvia, E. (2011). From women to objects: Appearance focus, target gender, and perceptions of warmth, morality and competence. Journal of Experimental Social Psychology, 47(3), 572-581. doi:10.1016/j. jesp.2010.12.020

Hyman. H. (1944). Do they tell the truth? The Public Opinion Quarterly, 8(4), 557-559.

IAAF. (2012). IAAF hyperandrogenism regulations - Explanatory notes - In force as from 1st May 2011. Retrieved from http://www.iaaf.org/about-iaaf/documents/ medical\#hyperandrogenism-and-sex-reassignment

IOC. (2012). IOC regulations on female hyperandrogenism: Games of the XXX Olympiad in London, 2012. Lausanne: International Olympic Committee.

Kidd, B. (2013). 'Seoul to the world, the world to Seoul' and Ben Johnson: Canada at the 1988 Olympics. Sport in Society, 16(4), 449-463. doi:10.1080/17430437.2013.785756

Lenskyj, H.J. (2003). Out on the field: Gender, sport and sexualities. Toronto: Canadian Scholars Press.

Lock, R.A. (2003). The doping ban: Compulsory heterosexuality and lesbophobia. International Review for the Sociology of Sport, 38(4), 397-411. doi:10.1177/1012690203384002

Mueller, S.M., Gorrow, T.R., \& Schneider, S.R. (2009). Enhancing appearance and sports performance: Are female collegiate athletes behaving more like males? Journal of American College Health, 57(5), 513-520. PubMed doi:10.3200/JACH.57.5.513-520

Peters, R.J., Adams, L.F., Barnes, J.B., Hines, L.A., Jones, D.E., Krebs, K.M., \& Kelder, S.H. (2005). Beliefs and social norms about ephedra onset and perceived addiction among college and male and female athletes. Substance Use \& Misuse, 40(1), 125-135. PubMed doi:10.1081/JA-200030517

Petróczi, A., \& Nepusz, T. (2011). Methodological considerations regarding response bias effect in substance use research: Is correlation between the measured variables sufficient? Substance Abuse Treatment Prevention and Policy, 6(1). doi:10.1186/1747-597X-6-1

Pfister, G., \& Gems, G. (2013). Fairy tales? Marion Jones, C.J. Hunter and the framing of doping in American newspapers. Sport in Society; Advance online publication.

Rudman, L.A., \& Glick, P. (2001). Prescriptive gender stereotypes and backlash toward agentic women. The Journal of Social Issues, 57(4), 743-762. doi:10.1111/0022-4537.00239

Sailors, P.R., Teetzel, S. J., \& Weaving, C. (2012). The complexities of sport, gender, and drug testing. The American Journal of Bioethics, 12(7), 23-25. doi:10.1080/1526516 1.2012 .680541

Schneider, A. (2000). On the definition of women in the sport context. In T. Tännsjö \& C. Tamburrini (Eds.), Values in sport (pp. 123-138). New York: E \& FN Spon.

Teetzel, S., \& Weaving, C. (2014). From silence to surveillance: The aftermath of a Canadian interuniversity sport doping scandal. Surveillance \& Society, 11(4), 481-493.

Tesch, Re. (1990). Qualitative research: Analysis types and software tools. Philadelphia, PA: Routledge Falmer.

Thorpe, H. (2012). 'Sex, drugs and snowboarding': (il)legitimate definitions of taste and lifestyle in a physical youth culture. Leisure Studies, 31(1), 33-51. doi:10.1080/0261 4367.2011.596556

Thualagant, N. (2012). The conceptualization of fitness doping and its limitations. Sport in Society, 15(3), 409-419.

Tredway, K. (2013). Judith Butler redux: The heterosexual matrix and the out lesbian athlete. Journal of the Philosophy of Sport, 41(2), 163-176. doi:10.1080/00948705.2013.785420

Warner, S., \& Dixon, M.A. (2013). Competition, gender and the sport experience: An exploration among college athletes. Sport Education and Society; Advance online publication.

Weaving, C., \& Teetzel, S. (2012). A sociocultural analysis of gender and sport. Retrieved from http://www.wada-ma.org/Documents/Education_Awareness/SocialScienceResearch/Research_Projects/2008/WEAVING_full_report_2008.pdf 
Yesalis, C.E., Bahrke, M., Kopstein, A., \& Barsukiewicz, C. (2000). Incidence of anabolic steroid use: A discussion of methodological issues. In C.E. Yesalis (Ed.), Anabolic steroids in sport and exercise (pp. 73-100). Champaign, IL: Human Kinetics.

Young, I.M. (2005). On female body experience: Throwing like a girl and other essays. New York: Oxford University Press.

\section{Appendix* \\ Interview Guide}

Prompts are indicated in italics

\section{Background Questions}

Can you describe your sports career? When did you start playing sports. . . and why? *ensure that the focus is university sport*

How would you describe femininity? What do you think femininity is/involves?

How would you describe masculinity? What do you think masculinity is?

*might need to say "cultural views/ or how does society portray masculinity and femininity*

Do your definitions of masculinity and femininity change when you think of athletes/sports or do they remain the same?

\section{Individual preparation and diet}

Can you describe how you prepared for your last major competition?

Do you always prepare the same way, eat the same thing?

Do you follow a special diet?

Are there any drink or foods you won't consume?

Where do you get your knowledge about your diet?

\section{University culture}

In your experience, what are the most common supplements and performanceenhancing drugs used by University athletes?

By females specifically (what do females use?)

By males specifically? (What do males use?)

*If they note a certain substance, ask for more explanation, sport specific? Used by males and females? During season, out of season?

*Also ask about nonathletes, if they stated a certain supplement, can ask if they noticed if that supplement was popular for male gym-goers (nonvarsity) and female gym-goers (nonvarsity)? Why?

Do you think one gender/sex uses more supplements or drugs than the other?

In your opinion, why do athletes use ergogenic aids?

a. What factors encourage athletes to use ergogenic aids? 
b. Why do female athletes use ergogenic aids?

c. Why do male athletes use ergogenic aids?

Do you think that certain performance enhancing drugs/ ergogenic aids are more suited for a specific gender/sex?

d. Why?

e. Do you consider some drugs more feminine or masculine than others?

f. Please provide examples and why you feel this way.

If a drug is considered gender neutral, that is, it is perceived as acceptable for all people to take, do you think that both males and female should use it? Can you think of any examples of a gender neutral drug? What would be a gender neutral drug?

\section{Size requirements}

Is your weight important in your sport?

Are there weight requirements?

Do you need to be thin to win? Or do you have to be bulky to be successful?

*If yes, do you feel an obligation to conform to/strive for a specific body shape?

How do you do it? So to get to that size what do people do?

\section{*The next series of questions can be sport specific.}

i.e., are there any positions in football that require you to be lean?

I.e. are there any position in rugby that you need to be super lean for?

Should women athletes use whatever they can to build stronger muscles, and get 'bigger,' if that is what is needed for their sports? Have you ever heard of any women athletes having to add weight for their sport?

How did they do it?

\section{Coping with injuries}

Have you ever been injured in your sport?

Did you listen to your body signals?

How do you feel if you do not train?

Have you ever competed injured on pain killers?

Do males use more pain killers? Why?

Do females use more pain killers? Why?

How do you think you handle general pain?

\section{Doping specific questions}

In society, a trend has emerged where more and more healthy people take medicines (examples, Sudafed, Tylenol cold and $f u$ ). Do you think it's reasonable that healthy people take drugs to optimize their performance in daily life, but elite athletes, like yourself, can't.?

Do you think that the doping regulations are fair at the university level? 
g. Do you think any substances should be added to the banned list?

h. Do you think any substances should be taken off the list?

Some say recreational drugs are banned in sport because they are taboo/illegal for many societies. So, it adds pressure on "sport" to clean up drug use in society. What do you think about recreational drugs being on the banned list for university athletes?

What role do you think the media should play with respect to doping? Does the media influence your attitude toward doping?

Do you think that uni athlete face suspicion of doping?

Have you ever heard of any rumours about student athletes doping?

Do you think there is enough testing in CIS sport?

\section{Health and risk}

How do you define a healthy university athlete?

Do you think being a university athlete is risky? (in terms of health)

Do you think male university athletes are more likely to experiment with different banned substances, methods. . . how/why/can you think of any examples. ...

Is there anything you would like to add on the discussion of university athletes and doping/ supplement usage?

*The interview guide was created by modifying some of the questions used in Gertrud Pfister's study Doping in Sport - An Issue of Gender and Society, funded by the Danish Agency for Science, Technology and Innovation (2008). 